\title{
A política de expansão da educação superior e a proposta de reforma universitária do governo Lula
}

\section{The higher education enlargement policy and the proposal for higher education reform of Lula's government}

\author{
Regina Maria Michelotto* \\ Rúbia Helena Coelho* \\ Maria Amélia Sabbag Zainko***
}

\section{RESUMO}

Este artigo faz um exame de alguns dos documentos sobre políticas para a educação superior, em especial La Educación Superior en los Países en Desarrollo: Peligros y promesas - produzido em conjunto pelo Banco Mundial e UNESCO, no ano de 2000. Tem-se como objetivo realizar uma discussão acerca das idéias relacionadas com a expansão, democratização e permanência na Educação Superior, a partir da proposta e das ações do Governo Lula, tendo como contraponto as idéias defendidas pelo Banco Mundial e pela UNESCO para as reformas educativas, em especial para os países em desenvolvimento.

Palavras-chave: Reformas na educação superior; Banco Mundial; UNESCO; países em desenvolvimento.

\footnotetext{
ABSTRACT

This text examines some documents about higher education politics especially "Higher education in developing countries: Peril and promises" - produced

" Professora /Pesquisadora do DEPLAE -UFPR.

${ }^{* *}$ Mestre em Educação pelo PPGE-UFPR.

${ }^{* * *}$ Professora /Pesquisadora PPGE- UFPR.
} 
MICHELOTTO, R. M.; COELHO, R. H.; ZAINKO, M. A. S. A politica de expansão...

by World Bank and UNESCO, 2000. The purpose of this article is to discuss the ideas about expansion, democratization and permanency the higher education in Lula's Govern in confront the ideas defended by World Bank and UNESCO and how these institutions translate for the educational reforms, especially for the developing countries.

Key-words: Reform in higher education; World Bank; UNESCO; developing countries.

\section{Introdução}

O presente artigo pretende enfocar uma das políticas do governo Lula para a Educação Superior: a "expansão" da oferta de vagas. Constata-se que, muitas vezes, esse dado é entendido como indicador de democratização do acesso ao nível superior de escolaridade. Cabe, então, buscar resposta à questão: expansão, nesse caso, é sinônimo de democratização? Estar-se-á, finalmente, no Brasil, promovendo uma abertura democrática das instituições superiores de educação para a população que vem sendo, historicamente, excluída desse direito?

A análise enfocará as políticas de expansão do atual governo, buscando estabelecer relação entre elas e as orientações que têm sido indicadas por organismos internacionais, especificamente o Banco Mundial e a UNESCO. Dos documentos que o Brasil tem recebido nas duas últimas décadas como diretrizes para a reforma universitária que, desencadeada no governo Fernando Henrique Cardoso, está sendo ultimada no atual, focalizar-se-á, principalmente, o documento: Higher education in developing countries: Peril and promisses (La Educación Superior em los Países em Desarollo: peligros y promesas), que veio a público no início do ano de 2000 e foi traduzido para a língua espanhola no final do mesmo ano. ${ }^{1}$

Esse documento é fruto da participação conjunta do Banco Mundial e da UNESCO, organizadores do "Grupo Especial sobre Educação Superior e Sociedade", que consistiu na reunião de experts de treze países, com o objetivo de discutir a educação superior - e seu futuro - nos países em desenvolvimento: "El Grupo Especial sobre Educación Superior y Sociedad

\footnotetext{
${ }^{1}$ A versão em espanhol foi a utilizada na presente análise.
} 
fue convocado por el Banco Mundial y la UNESCO para reunir expertos de trece países, con el propósito de explorar el futuro de la educación superior en el mundo en desarrollo".

Segundo seus elaboradores, baseia-se "na experiência e na convicção" (GRUPO ESPECIAL..., 2000, p.24) e é destinado aos responsáveis pelas políticas (policy makers), às autoridades do sistema de educação superior, às entidades responsáveis pelos credenciamentos e doações, à comunidade política e ao público em geral, dentre eles, os estudantes (GRUPO ESPECIAL..., 2000, p.23).

Pretende-se analisar as medidas que foram tomadas para a expansão de vagas na Educação Superior no Brasil, buscando esclarecer se podem ou não constituir indícios de um processo de democratização. Para tanto, faz-se necessária uma reflexão inicial sobre essa categoria.

\title{
Sobre a democratização da Educação Superior
}

A democratização da Educação Superior foi a grande pauta dos debates e manifestações que compuseram o cenário dos anos de 1950 e 1960 no Brasil. Aqui, como em muitos outros países no mundo, o desfecho da segunda guerra mundial, com a vitória das forças chamadas de democráticas, desencadeou uma onda de reivindicações, dentre elas a do acesso à escola, em geral.

\begin{abstract}
A pressão por mais e boas escolas gerou um aumento significativo no número de estudantes nos diversos graus de ensino, propiciando, por sua vez, condições de mais e melhor pressão pela democratização dos níveis mais altos, atingindo e forçando as "portas" da universidade, historicamente fechadas aos setores populacionais de menor poder aquisitivo. Cresciam as reivindicações por universidades mais acessíveis à população (MICHELOTTO, 1999, p. 21).
\end{abstract}

Nesse contexto, destacou-se um livro que se tornou inestimável e imprescindível para os estudantes em movimento, no Brasil: A Questão da Universidade, de Álvaro Vieira Pinto. 
MICHELOTTO, R. M.; COELHO, R. H.; ZAINKO, M. A. S. A política de expansão...

Escrito em 1961, permite sem dúvidas que se entenda por que foi editado pela UNE, ${ }^{2}$ já que contém uma viva conclamação contra a sociedade estratificada e injusta, e especificamente contra a universidade, que o autor considerava viveiro da classe dominante (PINTO, 1986, p. 32). Ali se encontra uma descrição que corresponde ao que se está entendendo por "democratização da universidade":

\begin{abstract}
... o aluno, ao iniciar a escola primária, e tão-somente por isso, já está habilitado a ingressar um dia na universidade. Só não pensa assim quem acredita que a escola primária se destina apenas a alfabetizar a massa dos trabalhadores, para os fazer (sic) trabalhar melhor para os seus atuais senhores, porém deixando-os nas condições de cultura rudimentar em que se encontram atualmente. A sociedade atual cultiva, como privilégio de classe, a "predestinação universitária". A autêntica democratização do ensino consiste precisamente em extinguir a predestinação universitária. Para tanto, é necessário que o processo educacional, em todas as suas fases, seja franqueado às massas trabalhadoras na totalidade, e estas atravessem, portanto, sem obstáculos intransponíveis, os pórticos das faculdades. (PINTO, 1986, p. 99).
\end{abstract}

Para tanto, era preciso perguntar por que alguns alunos entram para a universidade e por que milhões de outros não entram, reflexão essa que forjou a tese capital do livro: "a reforma universitária não diz respeito, primordialmente, aos alunos que estão na universidade, mas aos alunos que não estão, aos que nela não puderam ingressar" (PINTO, 1986, p. 20 e 22).

Vieira Pinto complementa, afirmando como questão primordial pensar-se em qual universidade se pretendia criar. Infere-se daí o direito de todos ao acesso a uma Educação Superior de qualidade indiscutível.

O movimento estudantil trouxe como mote esse sentido de democratização e se espalhou como estopim pelo mundo inteiro, em 1968. A revolta não se limitou a um dos dois grandes blocos contrapostos e envolvidos em uma "guerra fria", mas eclodiu com intensidade tanto em países de um pólo quanto de outro, o que “(...) constitui um dos aspectos mais inespera-

${ }^{2}$ UNE - União Nacional dos Estudantes, criada em 1937 para participação no Conselho Internacional dos Estudantes. (Cf. in: GURGEL, 1986, p. 38). 
dos e significativos de 1968" (новsваwм, 1998, p. 4-5). Tomou, porém, conotações diversas e provocou respostas políticas diferenciadas, conforme a situação. Na Alemanha, por exemplo, “(...) a proximidade do regime stalinista, por um lado, e a saturação da civilização e da propaganda americana facilitariam aos estudantes a recusa, ao mesmo tempo, do american way of life e do stalinismo autoritário" (MATOs, 1989, p. 29).

Outros países, como Itália, Bélgica, Espanha, EUA, Japão, França (considerada como cerne da revolta), Iugoslávia, Polônia, TchecoEslováquia, México, Venezuela, Colômbia, Uruguai e Argentina viram-se envolvidos nesse movimento. Segundo Matos, em um manifesto francês distribuído pelos estudantes estava escrito:

\begin{abstract}
Nós combatemos porque nos recusamos a nos tornarmos:
- professores a serviço da seleção no ensino, de que os filhos da classe operária são vítimas;

- sociólogos fabricantes de slogans para as campanhas eleitorais governamentais;

- psicólogos encarregados de fazer "funcionar" as "equipes" de trabalhadores "segundo os melhores interesses dos patrões";

- cientistas cujo trabalho de pesquisa será utilizado segundo os interesses exclusivos da economia do lucro. Nós recusamos este futuro de "cães de guarda". Nós recusamos os cursos que nos ensinam a nos tornarmos isso. Recusamos os exames e os títulos que recompensam os que aceitam entrar no sistema. Nós nos recusamos a melhorar a universidade burguesa. Nós queremos transformá-la radicalmente a fim de que de agora em diante ela forme intelectuais que lutem ao lado dos trabalhadores e não contra eles (мAтоs, 1989, p. 72).
\end{abstract}

Miozzi, analisando a situação na Itália, constata que a crítica extrapolou a questão educacional.

\begin{abstract}
As lutas estudantis se voltam contra o autoritarismo não mais só da escola e dos docentes, mas da cultura. Daqui o discurso sobre a seleção acabava rapidamente por transformar-se. Não se tratava mais de uma seleção, que, praticada pela escola e pelas suas estruturas tradicionais, impedia as massas de chegar à cultura. Era, ao invés, a cultura (...) por si só seletiva, porque
\end{abstract}


MICHELOTTO, R. M.; COELHO, R. H.; ZAINKO, M. A. S. A politica de expansão...

objetivada à organização do trabalho, aos modelos de vida e de consumo, aos valores da sociedade capitalista. Eis porque a necessidade de se "sair" da escola e atacar (...) o sistema (MIOZZI, 1993, p. 188, nota 40).

A análise feita, agora, à distância dos acontecimentos de 1968, permite a conclusão de que "se o objetivo de se destruir a velha sociedade e criar uma nova não foi atingido, não se pode afirmar que aquela permaneceu a mesma" (міснеlotто, 1999, p. 32) e nem se pode minimizar o caráter que tomou a democratização da Educação Superior nesse período.

A partir desse subsídio sobre democratização, pode-se encaminhar a reflexão para as atuais políticas de expansão de vagas nas Instituições de Educação Superior (IES) brasileiras, confrontadas com as orientações do Banco Mundial e da UNESCO.

\section{A questão da expansão: Banco Mundial/UNESCO}

As ações dos organismos aqui enfocados têm sido sobejamente analisadas e criticadas por muitos autores, não apenas do campo da Educação. O Banco Mundial é um dos principais organismos multilaterais internacionais de financiamento do desenvolvimento social e econômico. Foi concebido durante a Segunda Guerra Mundial, em Bretton Woods, Estado de New Hampshire (EUA). Atualmente é constituído por 183 países-membros, dentre os quais o Brasil. É formado por cinco organizações: o Banco Internacional de Reconstrução e Desenvolvimento (BIRD), a Associação Internacional de Desenvolvimento (AID), a Corporação Financeira Internacional (IFC), a Agência Multilateral de Garantia de Investimentos (AMGI) e o Centro Internacional para Acerto de Disputas de Investimento (CIADI).

Segundo seu discurso oficial, a meta principal da ação do Banco é reduzir a pobreza no mundo. As prioridades do Banco são, dentre outras: investir nos países em desenvolvimento, em especial no que diz respeito à saúde e à educação básicas; proteger o meio ambiente; originar reformas para a criação de um meio macroeconômico estável propício a investimentos e a planejamentos de longo prazo e contribuir para o desenvolvimento social, inclusão, boa governança e fortalecimento institucional como ele- 
mentos essenciais para a redução da pobreza. (http://www.obancomundial. org, 2005).

Entretanto, o discurso do Banco é veementemente desmascarado por diversos autores, dentre eles Soares:

\begin{abstract}
Após cinqüenta anos de operação e empréstimos de mais de 250 bilhões de dólares, a avaliação da performance do Banco Mundial é extremamente negativa. Este financiou um tipo de desenvolvimento econômico desigual e perverso socialmente, que ampliou a pobreza mundial, concentrou renda, aprofundou a exclusão e destruiu o meio ambiente. Talvez a mais triste imagem desse fracasso seja a existência hoje de mais de 1,3 bilhão de pessoas vivendo em estado de pobreza absoluta (SOARES, 2003, p.17).
\end{abstract}

De fato a interferência do Banco tem contribuído historicamente não para a diminuição da pobreza, mas sim para seu incremento; o Banco tem representado o papel de um importante auxiliar de política externa americana e tem interesse tanto na venda de projetos para os países quanto no financiamento dos projetos apresentados por estes que estejam de acordo com suas determinações, afinal de contas, o Banco Mundial, como qualquer outro banco, lucra - e muito - com os pagamentos dos empréstimos concedidos. Além disto, sendo que os empréstimos proporcionados pelo Banco são vinculados ao cumprimento de certas "condicionalidades" postas por esta agência, tornam-se eficientes mecanismos de implementação das políticas neoliberais nos diferentes países do globo (sHiRoma, 2004). A educação é uma das áreas em que o Banco tem concentrado suas ações: as reformas educacionais dos diferentes países têm se constituído em uma preocupação constante do Banco e um privilegiado meio de implementar tais políticas.

A UNESCO - Organização das Nações Unidas para a Educação, a Ciência e a Cultura - por sua vez, foi composta logo após a segunda guerra mundial com o propósito de contribuir para a construção da paz mundial (http://www.unesco.org.br). Na atualidade, cerca de 190 Estados-Membros a compõem. Sua área de atuação compreende a área da educação, das Ciências Naturais, Humanas e Sociais, da cultura, da comunicação e informação. 
MICHELOTTO, R. M.; COELHO, R. H.; ZAINKO, M. A. S. A política de expansão...

No documento aqui enfocado, La Educación Superior em los Países em Desarollo: peligros y promesas, é feita a defesa da necessidade de melhoria da qualidade da educação superior e ampliação do atendimento à demanda: "El Grupo Especial, en cuanto equipo de trabajo, opina que como primerísima prioridad, deberían realizarse esfuerzos urgentes para ampliar la cantidad y mejorar la calidad de la educación superior en los países en desarrollo". (GRUPO ESPECIAL..., 2000, p. 11-12 e 20). Porém, acrescenta, como adendo, que essa é condição para que os países em desenvolvimento participem e desfrutem da economia mundial:

Sobre la base de investigaciones y intensos debates que se llevaron a cabo durante dos años, el Grupo ha llegado a la conclusión de que si no se imparte más educación superior y cada vez de mejor calidad, a los países en desarrollo, les será cada vez más y más difícil beneficiarse de la economía mundial basada en el conocimiento. (GRUPO ESPECIAL..., 2000, p. 11).

Se a economia mundial baseia-se no conhecimento, o capital humano passa a ser considerado como fonte de riqueza, tanto atual como futura: "El conocimiento, las habilidades y el ingenio de los individuos son cada vez más decisivos para la economía mundial." (GRUPO ESPECIAL..., 2000, p.17). Ficam claros os objetivos de cunho econômico das orientações, o que as distancia da norma constitucional dos países em geral, do "direito público à educação", base do movimento da década de 1960.

O sistema de educação superior, segundo a defesa do Grupo, tem as seguintes funções:

- satisfacer la demanda de los estudiantes de que les sea impartida una educación cada vez de mejor nivel cultural, más compleja y la vez gratificante;

- preparar a las personas necesarias para dirigir una sociedad moderna y contribuir a su progreso;

- proporcionar un foro en que la sociedad pueda analizar sus problemas y encontrar las soluciones apropiadas; $y$

- proporcionar un ambiente adecuado al estudio y al desarrollo de la cultura y los valores de la sociedad (GRUPO ESPECIAL..., 2000, p. 95). 
Para atender à demanda, formar os líderes, estabelecer um foro de debate social e produzir um ambiente propício para o estudo e desenvolvimento de sua cultura e valores, a importância da educação superior consiste em: i) prover a um crescente número de estudantes conhecimentos e habilidades especializadas; ii) dotar de educação geral uma quantidade importante de estudantes; iii) ensinar aos estudantes não só o que é conhecido, mas também a maneira como poderão atualizar-se no futuro ("aprender a aprender").

É inegável o caráter positivo e progressista de tais orientações e uma leitura um pouco mais descuidada e rápida pode indicar que está sendo proposta uma verdadeira democratização da Educação Superior aos países devedores. Porém (e já se esperava que houvesse um "porém"), o encaminhamento de tais propostas, que vem a seguir, indica o real objetivo desse grupo para os países devedores: a expansão da educação superior, segundo o diagnóstico realizado pelo Grupo, encontra uma série de dificuldades, dentre elas a grande demanda de financiamento público necessária para tanto. Defende, então, que é preciso que as ações sejam "criativas" e "consistentes" e que sejam baseadas em uma "nova visão" de ensino superior, melhor planificação e padrões mais altos de gestão. Além disto, alega que é primordial que as forças de todos os atores - públicos e privados - sejam utilizadas para que a expansão seja concretizada. Tendo em vista que, para o Grupo, um sistema puramente estatal não se mostra apropriado para satisfazer as demandas de excelência e acesso, propõe que o modelo de financiamento seja misto para elevar ao máximo os ingressos provenientes do setor privado, de instituições e indivíduos que levem a cabo missões filantrópicas, bem como dos estudantes (GRUPO ESPECIAL..., 2000, p. 1213).

A educação superior passa a ser constituída por um sistema estatal, um sistema privado e um híbrido. Isto proporciona que a expansão da oferta do ensino superior se dê com pouco ou nenhum financiamento público e que ocorra uma maior adequação deste nível de ensino ao mercado, pela diferenciação entre as instituições: i) horizontal (financiamento público e/ou privado) e ii) vertical (distintos tipos de instituições).

Los sistemas de educación superior no solo se han expandido en todo el mundo, sino que la naturaleza misma de los establecimientos ha experimentado simultáneamente un cambio, como resultado de un proceso de diferenciación. Este proceso puede darse en sentido vertical, conforme 
MICHELOTTO, R. M.; COELHO, R. H.; ZAINKO, M. A. S. A politica de expansão...

proliferan distintos tipos de instituciones, es decir, a medida que junto a las universidades tradicionales de investigación, van apareciendo institutos politécnicos, escuelas profesionales, establecimientos que otorgan grados pero no realizan investigación, y centros de educación popular. La diferenciación puede darse también en sentido horizontal, merced a la creación de establecimientos manejados por agentes privados, tales como instituciones con fines de lucro, organizaciones filantrópicas y otras entidades sin fines de lucro, como asimismo, agrupaciones religiosas. El auge del aprendizaje a distancia, modalidad que cobra cada vez mayor importancia, es otro ejemplo de diferenciación, que se da tanto en sentido vertical como horizontal (GRUPO ESPECIAL..., 2000, p. 32).

A constituição de um sistema diferenciado, composto por instituições que têm diferentes fins, mostra-se em condições para responder às necessidades do contingente variado de estudantes e do desenvolvimento dos países, em função das (sempre novas) demandas de maior diversificação profissional provenientes do mundo do trabalho; afinal, a flexibilidade é tida como um dos requisitos da eficácia e permite a adaptação rápida às mudanças:

El desarrollo económico está asociado en general a una división más especializada del trabajo, y las instituciones de educación postsecundaria pueden cumplir una función esencial en cuanto a la entrega de las habilidades correspondientes. (...) Las instituciones públicas y privadas han respondido a esa demanda con la creación de programas académicos que distribuyen a los estudiantes en un rango más amplio de competencias. Algunos de estos nuevos programas les permiten, por ejemplo, titularse en forma relativamente rápida en especialidades de nivel inferior (GRUPO ESPECIAL..., 2000, p. 34-35).

No sistema de educação superior - composto pelas IES, pelas organizações que participam diretamente em seu financiamento, gestão ou manejo e pelas regras (formais e informais) que deliberam sobre seu funcionamento (GRUPO ESPECIAL..., 2000, p. 51) -, cada instituição de ensino superior cumpre um papel determinado: as universidades de pesquisa que, em 
geral, são públicas e não perseguem fins lucrativos, têm como meta alcançar a excelência, são extremamente seletivas quanto à admissão de alunos e se regem por padrões internacionais (GRUPO ESPECIAL..., 2000, p. 53); às universidades regionais - que podem fazer parte tanto do setor público quanto do privado - cabe a produção de um grande número de graduados, tendo como fim sua incorporação imediata no mercado de trabalho. O documento incentiva que desenvolvam cursos de curta duração, por exemplo, de dois anos (GRUPO ESPECIAL..., 2000, p. 53-54). Os institutos profissionais e os institutos técnico-profissionais ${ }^{3}$ - estabelecimentos privados com fins lucrativos, que operam, portanto, como empresas - são responsáveis pela "formação técnica" e pela "formação para trabalhos específicos" (GRUPO ESPECIAL..., 2000, p. 54). O fato de serem privados colabora para que estejam em íntima relação com as forças do mercado.

As universidades virtuais e a educação à distância são veementemente defendidas pelo Grupo, graças à sua "viabilidade econômica": "las nuevas tecnologías basadas en la utilización de satélites e Internet prometen llevar este tipo de enseñanza a grupos cada vez más numerosos, y no sólo a quienes viven en zonas remotas y escasamente pobladas, sino también en localidades con aglomeraciones urbanas." Ademais, defende que este se "constituye un poderoso canal para integrar a la educación a grupos hasta ahora excluidos" (GRUPO ESPECIAL..., 2000, p. 34). Entretanto, o Grupo salienta a necessidade de sua integração ao sistema de educação superior geral e a existência de padrões de acreditação e qualidade apropriados.

A estratificação da educação superior constitui-se como a solução para a expansão deste nível de educação, bem como para sua adequada articulação com as necessidades de formação demandadas pelo mercado: "Un establecimiento estratificado es un híbrido que concilia las metas de excelencia y de educación masiva, y que permite el logro de ambas dentro de un sistema único sin necesidad de incurrir en grandes gastos." (GRUPO ESPECIAL..., 2000, p. 55). Sempre está presente a preocupação com os gastos, de forma a obrigar os países-alvo desse documento a manter reservas capazes de garantir o pagamento das dívidas.

A constituição de um sistema diferenciado e diversificado de educação superior requer que a ação estatal seja bem definida: sua intervenção é essencial, contudo não deve ser excessiva.

${ }^{3}$ Os institutos técnico-profissionais, embora sejam considerados como paralelos ou parte da educação secundária, são tratados pelo documento como parte do sistema da educação superior. 
MICHELOTTO, R. M.; COELHO, R. H.; ZAINKO, M. A. S. A política de expansão...

As universidades públicas precisam desenvolver novos métodos para arrecadação de fundos, afinal os recursos estatais são limitados. O documento sugere como inestimáveis estratégias para obtenção destes recursos a "oferta de programas de formación de ejecutivos, la comercialización de los servicios especializados del personal docente o la prestación de diversos otros servicios - como son, por ejemplo, la realización de exámenes de laboratorio y el arrendamiento de instalaciones" (GRUPO ESPECIAL..., 2000, p. 64-65).

O próprio Grupo admite que "los programas más extensos de educación humanista no son para todos, ni siquiera para la mayoría de los estudiantes, sino para los más inteligentes y motivados; un amplio espectro del resto de los estudiantes podría acceder a programas menos intensivos" (GRUPO ESPECIAL..., 2000, p. 100-101).Entretanto, para justificar esta "diferenciação" utiliza-se da do conceito de meritocracia:

\begin{abstract}
No obstante, subsiste el problemas de las diferencias de capacidad; no todas las personas son aptas para acceder al mismo nivel de capacitación o para realizar las mismas tareas, dado que algunas son más difíciles que otras. De esto se desprende que la desigualdad en algunas áreas es natural. Educar a los más capaces para que ocupen posiciones de liderazgo en todas las esferas de la vida debe responder al interés nacional, y es uno de los aspectos más importantes de la estratificación. (GRUPO ESPECIAL..., 2000, p. 101)
\end{abstract}

Os indivíduos aos quais se dirige o nível mais refinado de educação geral são aqueles que são formados para exercerem posições de liderança e atuarem na sociedade como cidadãos instruídos e trabalhadores capacitados para a indústria, o governo, a política e o mundo acadêmico (GRUPO ESPECIAL..., 2000, p. 99).

O Grupo defende que para a ampliação do atendimento da educação superior, bem como para sua melhor adequação ao mercado, é necessário que as instituições sejam capazes de captar recursos financeiros adicionais. A maior parte destes, entretanto, deverá ser proveniente dos próprios países em desenvolvimento.

As instituições precisam realizar uso racional e eficiente dos recursos existentes, bem como um melhor uso do capital físico e humano, afinal "los socios externos prefieren invertir su dinero donde sea bien aprovechado" (GRUPO ESPECIAL..., 2000, p. 109). E conclui afirmando que, para que a 
reforma proposta neste documento seja efetivada, é de fundamental importância que seja constituído um diálogo transparente entre todos os interessados, a saber: os professores, a indústria, o governo, os futuros estudantes, dentre outros (GRUPO ESPECIAL..., 2000, p. 109).

\title{
A expansão no Brasil e a Reforma Universitária no Governo Lula da Silva
}

Nas últimas quatro décadas, a educação superior no Brasil passou por fases de forte expansão de instituições e de matrículas, com destaque para os anos 70, a partir dos quais teve início o processo de privatização da Educação Superior no país. Florestan Fernandes denuncia que, no período do governo militar:

\begin{abstract}
... as linhas escolhidas para atingir o incremento [das matrículas] concorreram para aumentar, em vez de corrigir ou de atenuar, as contradições e as anomalias do padrão brasileiro de ensino superior. Elas propiciaram, em especial, a revitalização das escolas superiores isoladas, em um novo contexto de comercialização irrefreada e de degradação sistemática do ensino superior (FERNANDES, 1975, p. 39).
\end{abstract}

Os dados atuais confirmam que esse direcionamento não só foi mantido como se acentuou intensamente.

No período 1991-2004, o número de instituições privadas cresceu $267 \%$ no território nacional. Em relação ao número de matrículas, a diferença é bem maior. A média brasileira, para esse quesito, apresenta uma variação de 311\% no período de 1991 a 2004.

O MEC registrou, em 2004, conforme os dados do Censo da Educação Superior, a abertura no país de seis novos cursos de nível superior por dia. Do total de matrículas em cursos de graduação presencial, 37\% se concentraram nas áreas de Administração, Direito e Pedagogia. Considerando-se a ampla variedade de opções proporcionadas pelas diversas instituições dos setores público e privado, pode-se concluir que a oferta obede- 
MICHELOTTO, R. M.; COELHO, R. H.; ZAINKO, M. A. S. A política de expansão...

ce a critérios que podem não coincidir com as demandas das regiões onde essas instituições estão instaladas. Coincidência ou não, os cursos mais oferecidos são os que demandam menos investimento em laboratórios e materiais.

A análise dos dados oficiais sobre o ensino superior, compilados no Censo 2004, possibilita a identificação de algumas características que aproximam o modelo brasileiro de algumas tendências mundiais do ensino superior. Segundo Dias Sobrinho (apud COELho; ZaInKo, 2005, p. 51), "não se pode falar de um sistema global de educação superior, mas é possível vislumbrar aspectos semelhantes ou tendentes a uma certa convergência nas experiências levadas a cabo em muitos países."

Nas últimas quatro décadas, conforme já enfatizado, a educação superior no Brasil passou por duas fases de forte expansão. A primeira delas coincidiu exatamente com o período militar. De 1964 a 1980 o número de matrículas nesse nível de ensino aumentou quase dez vezes. Contraditoriamente, no período subseqüente, de abertura política e redemocratização do país (1980-1995), o sistema apresentou um crescimento meramente vegetativo. Em 1980, havia 882 instituições de ensino superior no país. Em 1995, apenas 12 instituições tinham se agregado ao sistema, contabilizando um modesto crescimento de $1,36 \%$ no período.

A segunda fase de expansão iniciou a partir de 1995. Na última década, houve uma verdadeira explosão de crescimento do ensino superior no Brasil. Essa grande expansão do sistema nacional ocorreu em razão do crescimento da rede privada e, nos anos recentes, em virtude do processo de diversificação das instituições.

A análise de todos os indicadores disponibilizados pelo INEP demonstra que no Brasil o sistema privado cresceu 151,6\% de 1996 a 2004.

GRÁFICO 1 - CRESCIMENTO DAS INSTITUIÇÕES DE ENSINO SUPERIOR NO BRASIL - 1991-2004

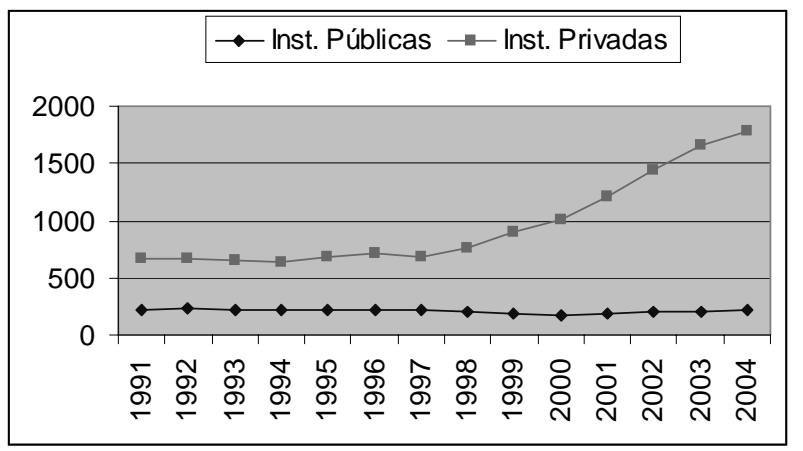


E é em função desse crescimento às avessas, porque excludente, que o documento Uma Escola do tamanho do Brasil, que traz os compromissos do Governo Lula, enfatiza a necessidade de ampliação do acesso à educação superior para todos os que a ela demandarem e preconiza uma universidade comprometida com a inclusão social.

Era preciso reverter o processo de deterioração acentuada que atingia o ensino superior desde os anos 90. A diminuição dos investimentos públicos em educação em todos os níveis e os sucessivos cortes orçamentários atingiram em cheio o sistema universitário federal, impedindo sua expansão e provocando o sucateamento das universidades existentes.

Segundo dados da Associação Nacional de Dirigentes das Instituições Federais de Ensino Superior (Andifes), no período de 1995-2001, as 54 instituições federais de ensino superior públicas perderam $24 \%$ dos recursos para custeio (pessoal, água, luz telefone e materiais diversos) e 77\% de recursos para investimento em salas de aulas, laboratórios, computadores e acervo bibliográfico, apesar do número de alunos ter aumentado. Tudo isso numa fase em que os dados oficiais registram um grande crescimento de cursos e matrículas, o que se poderia configurar como uma expansão privada da educação superior.

Mas, se por um lado a expansão do ensino privado não é negativa porque teoricamente cria possibilidades de acesso ao ensino superior a uma parcela maior da população em muitas regiões do país, por outro ela se deu em detrimento da qualidade, com a criação de inúmeras escolas sem corpo docente qualificado e sem a infra-estrutura mínima necessária ao seu funcionamento. No entanto, a maioria das instituições privadas se dedica apenas ao ensino, sem apoiá-lo na produção do conhecimento e nas atividades de extensão.

Além disso, apesar do crescimento de matrículas nos cursos de graduação nos últimos anos, o Brasil, com menos de $8 \%$ dos jovens entre 20 e 24 anos matriculados em instituições de ensino superior, está muito atrasado em relação aos países de nível de desenvolvimento semelhante. A proposta de elevar para 30\% constante do documento "Uma escola do tamanho do Brasil" fazia sentido, uma vez que buscava resolver problema apontado pelo diagnóstico.

Reconhecendo o papel estratégico das universidades, em especial as do setor público, para o desenvolvimento econômico e social, o governo Lula adotou uma série de medidas com o objetivo de expandir a oferta de ensino superior, principalmente o de caráter público. Assim, o Programa Expandir, desenvolvido pela Secretaria de Educação Superior do MEC, prevê 
MICHELOTTO, R. M.; COELHO, R. H.; ZAINKO, M. A. S. A política de expansão...

a criação de dez universidades federais (duas a partir do zero, duas através do desmembramento de universidades existentes e seis a partir de escolas e faculdades especializadas) e 43 campi universitários em diversas regiões do país.

As propostas de "expansão" não se limitaram, porém, às criações de novas universidades públicas e novos "campi", a partir do mesmo modelo de estrutura organizacional que já se mostrou inadequado em função das novas demandas, mas incluem também a ampliação do acesso nas instituições privadas por meio do PROUNI. Mediante renúncia fiscal, as instituições privadas oferecem bolsas para alunos carentes. Vários autores têm se dedicado a analisar o PROUNI como perspectiva de ampliação do acesso à educação superior e, portanto, como um instrumento de democratização da educação superior. Mas, as análises invariavelmente questionam a sua eficiência como política pública, pois a sua concepção é pouco consistente no que tange à permanência do estudante, elemento fundamental para sua democratização.

Segundo Cattani et al., 2006 o PROUNI “orienta-se pela concepção de assistência social, oferecendo benefícios e não direitos aos bolsistas. Os cursos superiores ofertados nas IES privadas e filantrópicas são, em sua maioria, de qualidade questionável e voltados às demandas imediatas do mercado".

No afã de se aproximar da meta do PNE de $30 \%$ da população de 18 a 24 anos freqüentando cursos de nível superior, o Governo Lula define estratégias que conflitam com as próprias prioridades estabelecidas para o período 2003-2006.

Um dos principais exemplos encontra-se na política de avaliação articulada com a regulação que concebeu e implantou o Sistema Nacional de Avaliação da Educação Superior (SINAES). O Novo sistema foi debatido com a sociedade, aperfeiçoado e legalizado pela Lei $\mathrm{n}^{\circ} 10.861$, de 14 de abril de 2004 e Portaria MEC no 2.051, de 09 de julho de 2004.

Paralelamente às discussões do SINAES e diante da necessidade de se rever o papel da universidade brasileira, vários encontros foram realizados, dentre os quais destacam-se: Por que e como Reformar a Universidade Brasileira, em agosto de 2003, e a Universidade XXI, seminário internacional realizado em novembro de 2003, ambos em Brasília.

Os subsídios obtidos com as contribuições de intelectuais de primeira linha do país e do exterior deveriam fornecer elementos consistentes para a proposta de uma nova lei de reforma universitária no Brasil. 
Durante todo o ano de 2004, o MEC, por meio de oitivas, debates, apresentação de documentos buscou mobilizar a comunidade acadêmica e a sociedade para a elaboração de um modelo de universidade mais consentâneo com as necessidades de um país em desenvolvimento e que carece de um sistema de educação superior comprometido com a qualidade.

Para tanto, foi necessário conduzir estudos que viabilizassem um novo olhar sobre a essência de uma proposta de Reforma Universitária como elemento de sustentação de uma política de qualidade e inclusão social, formulando estratégias de ação que garantissem as universidades, independentemente de seus vínculos administrativos, como espaços públicos de educação e formação e (in)formação de cidadãos.

A Reforma Universitária é, por um lado, exigência do tempo presente, quer seja pelo impacto da explosão do conhecimento nos processos formativos, quer seja pela necessidade da universidade repartir com a população que a criou e a mantém os resultados de suas pesquisas e toda produção do conhecimento que se dá nas salas de aulas, contribuindo assim de maneira decisiva para a resolução dos problemas locais, regionais e nacionais. Mas, por outro lado, tem se caracterizado como uma das exigências dos organismos internacionais aos países em desenvolvimento.

A exposição de motivos que acompanha a terceira versão (revista e aperfeiçoada) do anteprojeto de lei, encaminhado ao excelentíssimo senhor Presidente da República, enfatiza que:

\begin{abstract}
a valorização da universidade pública e defesa da educação como um direito de todos os brasileiros é para o Ministério da Educação meta de extrema relevância, já que tem clareza sobre o papel estratégico que a universidade desempenha na construção de um novo projeto de desenvolvimento, que compatibilize crescimento sustentável com justiça social.
\end{abstract}

Não é isso o que se observa nas propostas em desenvolvimento. Tanto a expansão, sem um projeto pedagógico inovador, carece de qualidade e desperdiça a oportunidade de expandir o acesso com a garantia da permanência e da pertinência dos processos de formação do cidadão e do profissional demandado pela sociedade contemporânea, quanto a redução da ociosidade nas instituições privadas por meio da destinação de vagas ao PROUNI, 
MICHELOTTO, R. M.; COELHO, R. H.; ZAINKO, M. A. S. A política de expansão...

representam um incremento no número de universitários, mas não avançam no que concerne à democratização do acesso ao ensino superior e à tão almejada justiça social.

No momento em que o anteprojeto encontra-se aguardando a sua discussão no âmbito do Congresso Nacional e a sua transformação em lei ainda passará pelo crivo da sociedade, é fundamental que se tenha presentes as determinações contidas nos documentos de UNESCO e Banco Mundial para não se incorrer no erro de colocá-las em prática tal como concebidas.

É sim de se esperar que a participação das comunidades interna e externa no aperfeiçoamento da proposta se faça muito menos em função de interesses corporativos e muito mais na discussão de projetos políticopedagógicos para cursos comprometidos com os interesses e as necessidades da população.

\section{REFERÊNCIAS}

ANDERSON, P. Balanço do neoliberalismo. In: SADER, E.; GENTILI, P (org.). Pósneoliberalismo: as políticas sociais e o Estado democrático. Rio de Janeiro: Paz e Terra, 1998.

CATANI, A. M. et al. PROUNI: democratização do acesso às instituições de ensino superior? Curitiba, Educar em Revista, n. 28, jul./dez. 2006.

CHAUÍ, M. Escritos sobre a universidade. São Paulo: UNESP, 2001.

. Universidade em ruínas. In: TRINDADE, H. (org.) Universidade em ruínas: na república dos professores. Petrópolis: Vozes, 1999.

COELHO, R. H.; ZAINKO, M.A.S. Os Fundamentos das Reformas de Estado e da Avaliação da Educação Superior .Revista Avaliação, v. 10, n. 4, dez. 2005, p. 52.

CORAGGIO, J. L. Propostas do Banco Mundial para a educação: sentido oculto ou problema de concepção? In: TOMMASI, L.; WARDE, M. J.; HADDAD, S. (org.) $O$ Banco Mundial e as políticas educacionais. São Paulo: Cortez, 2003.

FERNANDES, F. Universidade brasileira: reforma ou revolução? São Paulo: Alfa-Omega, 1975.

GENTILI, P (org.) Pedagogia da exclusão: crítica ao neoliberalismo em educação. Petrópolis: Vozes, 2001. 
GRUPO ESPECIAL SOBRE EDUCACIÓN SUPERIOR Y SOCIEDAD. La Educación Superior en los Países en Desarollo: Peligros y promesas. 2000. Disponível em: http:// worldbank.org (acessado em 01/12/2004)

GURGEL, R. M. Extensão universitária: comunicação ou domesticação? São Paulo: Cortez, 1986.

http://www.obancomundial.org (acessado em 01/12/2004).

http://www.unesco.org.br (acessado em 01/12/2004).

HOBSBAWM, E. O ano em que os profetas falharam. In: Folha de São Paulo, 10/05/ 1998 - cad. 5, p. 4-5.

LAUGLO, J. Crítica às prioridades e estratégias do Banco Mundial para a educação. In: Cadernos de Pesquisa, n. 99. Fundação Carlos Chagas, mar., 1997.

LEHER, R. Para silenciar os campi. Educação e Sociedade, 88, vol. 25, Campinas, 2004.

. Expansão Privada do Ensino Superior e Heteronomia Cultural: um difícil início de século. In: DOURADO, L. F.; CATANI, A. M.; OLIVEIRA, J. F. Políticas e gestão da Educação Superior. São Paulo: Xamã e Goiânia: Alternativa, 2003.

MATOS, Olgaria C. F. Paris 1968 - As barricadas do desejo. Coleção Tudo é História, n. 9, 3. ed. São Paulo: Ed. Brasiliense 1989.

MICHELOTO, R. M. A Liberação do acesso e a extensão como estratégias de democratização da Universidade: A experiência da itália e do Brasil. 1999. Tese (Doutorado) Departamento de Educação, Universidade Federal de São Carlos (UFSCar), São Paulo.

MIOZZI, U. Massimo - Lo Sviluppo Storico Dell'Università Italiana. Firenze: Le Monier, 1993

PINTO, Álvaro V. A questão da Universidade. Reed. São Paulo: Cortez Ed., 1986.

SGUISSARDI, V. (org.) Educação superior: velhos e novos desafios. São Paulo: Xamã, 2000.

O desafio da educação superior no Brasil: quais são as perspectivas? In: SGUISSARDI, V. (org.) Educação superior: velhos e novos desafios. São Paulo: Xamã, 2000.

; SILVA JR , J. R. Novas faces da Educação Superior no Brasil - Reforma do Estado e mudança na produção. Bragança Paulista: EDUSF, 1999.

. A Universidade neoprofissional, heterônoma e competitiva. In: MANCEBO, D.; FÁVERO, M. L. (org.) Universidade, políticas, avaliação e trabalho docente. São Paulo: Cortez Ed. 2004.

SHIROMA, E O. [O que você precisa saber sobre...] Política Educacional. Rio de Janeiro: DP\&A, 2004. 
MICHELOTTO, R. M.; COELHO, R. H.; ZAINKO, M. A. S. A politica de expansão...

SIQUEIRA, A. O documento “conjunto" Banco Mundial-UNESCO sobre Ensino Superior. In: Cipedes, $\mathrm{n}^{\circ} 1$ (12) - Mar. 2001, separata da Revista Avaliação. Campinas: Unicamp, v. 6, n. 1, mar, 2001.

SOARES, M. C. C. Banco Mundial: políticas e reformas. In: TOMMASI, L.; WARDE, M. J.; HADDAD, S. (org.) O Banco Mundial e as políticas educacionais. São Paulo: Cortez, 2003.

TRINDADE, H. (org.) Universidade em ruínas: na república dos professores. Petrópolis: Vozes, 1999.

. As metáforas da crise: da "universidade em ruínas" às universidades na penumbra" na América Latina. In: GENTILI, P. (org.) Universidades na penumbra: neoliberalismo e reestruturação universitária. São Paulo: Cortez, 2001.

. UNESCO e os cenários da educação superior na América Latina. In: TRINDADE, H. (org.) Universidade em ruínas: na república dos professores. Petrópolis: Vozes, 1999.

UMA ESCOLA DO TAMANHO DO BRASIL - site Instituto Cidadania, acessado em 15 de julho de 2006.

ZAINKO, M. A. S.;, GISI, M. L. (Org). Políticas e gestão da Educação Superior. Curitiba: Champagnat, Florianópolis: Insular, 2003.

Texto recebido em 18 maio 2006 Texto aprovado em 20 jun. 2006 